\title{
OPEN Gender differences of clinical and polysomnographic findings with obstructive sleep apnea syndrome
}

\author{
Xiaobo Zhou ${ }^{1 凶}$, Bo Zhou ${ }^{1}$, Zhe $\mathrm{Li}^{1,2}$, Qiao $\mathrm{Lu}^{1}$, Shaoping $\mathrm{Li}^{1}$, Zhongyin $\mathrm{Pu}^{1}$ \& Fang $\mathrm{Luo}^{1}$
}

Obstructive sleep apnea syndrome (OSAS) is underdiagnosed in females and gender differences in clinical and polysomnographic findings have not been widely investigated in China. We examined clinical and polysomnographic differences between males and females with OSAS in order to determine the influence of gender on clinical presentation and polysomnographic features. Data were collected from 303 adult patients diagnosed with OSAS (237 males and 66 females) from 2017 to 2019. All the patients completed physical examination, Epworth sleepiness scale, and whole night polysomnography. AVONA, univariate and multivariate logistic regression analyses were conducted to assess gender differences of clinical and polysomnographic findings with OSAS. $P<0.05$ was statistically significant. The average age was $48.4 \pm 12.6$ years for females and $43.4 \pm 12.4$ years for males. Compared with female patients with OSAS, male patients were taller and heavier, had higher systolic blood pressure in the morning, shorter duration of slow wave sleep, more micro-arousal events, greater $\mathrm{AHI}$, and more complex sleep apnea events. There are obvious gender differences of clinical and polysomnographic characteristics with OSAS. Understanding gender differences will contribute to better clinical recognition of OSAS in females as well as the provision of proper health care and therapeutic practice.

Obstructive sleep apnea syndrome (OSAS) is a common sleep disorder characterized by repetitive episodes of partial or complete upper airway obstruction, resulting in sleep fragmentation and cardiovascular comorbidity ${ }^{1}$. OSAS was thought to be very rare in females and a great number of epidemiological studies of OSAS included only males ${ }^{2,3}$. According to studies in the past, the male to female prevalence ratio of OSAS varied from 2:1-4:1 in the community to $8: 1$ or greater in the clinics ${ }^{4-6}$. It has been estimated that females with OSAS was underdiagnosed to a large extent ${ }^{7}$.

Inadequate understanding of sex difference in OSAS might be the root of the gender bias observed in OSAS. The National Sleep Disorders Research Plan ${ }^{8}$ acknowledged that there was a lack of inclusion of women in the past studies and has given priority to the exploration of gender differences in sleep disorders. Understanding gender differences in OSAS has currently been an important issue.

Gender differences in clinical and polysomnographic (PSG) findings have not been widely investigated outside North America ${ }^{9}$, and Chinese patients with OSAS may have different clinical features from North American patients. Therefore, the present study was undertaken to examine the gender differences in clinical and PSG findings in a subset of Chinese adult patients with OSAS and compare the findings with data from the literature.

\section{Results}

A total of 303 adult patients who were diagnosed with OSAS based on PSG were the focus of the study. The male to female ratio was 3.59:1 with respect to 237 males and 66 females. The mean age was $43.4 \pm 12.4$ years for males and $48.4 \pm 12.6$ years for females. $24.2 \%$ of females and $7.5 \%$ of males were older than 60 years (Table 1 ).

Regarding body mass index (BMI) distribution, in the normal weight group, females were proportionally more (57.6 vs $40.9 \%$ ), whereas in the overweight group, males were proportionally more (45.9 vs $28.7 \%$ ). The proportion of obese patients was similar in male and female groups (11.4\% vs $10.7 \%$ ) (Table 2).

${ }^{1}$ Department of Psychosomatics, Sichuan Academy of Medical Sciences \& Sichuan Provincial People's Hospital, Chengdu, China. 'Department of Psychiatry, Panzhihua Shengtai Rehabilitation Hospital, Panzhihua 617000, China. ${ }^{\square}$ email: zhouxiaobo2019@163.com 


\begin{tabular}{|l|l|l|l|l|}
\hline & Female $(\mathbf{n}=\mathbf{6 6})$ & Male $(\mathbf{n}=\mathbf{2 3 7})$ & Statistics & $\boldsymbol{P}$ \\
\hline Young age (18-44) & $24(36.4)$ & $129(54.4)$ & & \\
\hline Middle age (45-59) & $26(39.4)$ & $90(29.7)$ & & \\
\hline Young old age (60-74) & $16(24.2)$ & $15(6.3)$ & & \\
\hline Old age (>75) & 0 & $3(1.2)$ & & \\
\hline Mean (SD) & $48.4(12.6)$ & $43.4(12.4)$ & F $=8.360$ & $0.004^{* \star}$ \\
\hline
\end{tabular}

Table 1. The age distribution of all the patients in genders. ${ }^{\star \star} P<0.05$.

\begin{tabular}{|l|l|l|l|l|}
\hline BMI $\left(\mathbf{k g} / \mathbf{m}^{\mathbf{2}}\right)$ & Female $(\mathbf{n}=\mathbf{6 6})$ & Male $(\mathbf{n}=\mathbf{2 3 7})$ & Statistics & $\boldsymbol{P}$ \\
\hline$<18.5$ Underweight & $2(3.0)$ & $3(1.3)$ & & \\
\hline $18.5-25$ Normal weight & $38(57.6)$ & $97(40.9)$ & & \\
\hline $25-30$ Overweight & $19(28.7)$ & $109(45.9)$ & & \\
\hline $30-40$ Obesity & $7(10.7)$ & $27(11.4)$ & & \\
\hline$>40$ Pathological obesity & $0(0)$ & $1(0.5)$ & & \\
\hline Mean (SD) & $24.6(3.7)$ & $25.9(3.5)$ & $\mathrm{F}=7.420$ & $0.007^{* *}$ \\
\hline
\end{tabular}

Table 2. BMI distribution of all the patients in genders. ${ }^{\star *} P<0.05$.

According to univariate and multivariate logistic regression analyses (Tables 3 and 4), compared with female patients with OSAS, male patients were taller $(157.5 \pm 5.0 \mathrm{~cm}$, versus $169.8 \pm 6.0 \mathrm{~cm}$, respectively) and heavier $(61.1 \pm 9.6 \mathrm{~kg}$ versus $74.9 \pm 11.5 \mathrm{~kg}$, respectively). Male patients had higher systolic blood pressure in the morning (119.4 $\pm 13.6 \mathrm{mmHg}$ versus $124.3 \pm 16.1 \mathrm{mmHg}$, respectively), shorter duration of slow wave sleep (SWS) $(52.7 \pm 41.5 \mathrm{~min}$ versus $37.8 \pm 27.3 \mathrm{~min}$, respectively), more micro-arousal events $(100.1 \pm 77.0$ versus $161.2 \pm 125.5$, respectively), more complex apnea events ( $2.7 \pm 6.2$ versus $18.2 \pm 46.3$, respectively). Apnea-hypopnea index (AHI) during total sleep time (TST) was greater in males than in females $(24.3 \pm 19.4$ min versus $33.9 \pm 25.5 \mathrm{~min}$, respectively).

TST was similar in male and female patients ( $455.1 \pm 68.7 \mathrm{~min}$ versus $451.7 \pm 69.8 \mathrm{~min}$, respectively). There were no gender differences in REM sleep stage, $\mathrm{N}_{1}$ and $\mathrm{N}_{2}$ sleep duration $(67.4 \pm 30.8$ min versus $71.9 \pm 28.3 \mathrm{~min}$, respectively, $331.5 \pm 67.8$ min versus $359.8 \pm 240.6 \mathrm{~min}$, respectively). Sleep latency of N1 and N2 was similar in females and males $(14.1 \pm 15.4 \mathrm{~min}$ versus $9.4 \pm 17.3 \mathrm{~min}, 23.9 \pm 29.9 \mathrm{~min}$ versus $16.7 \pm 24.1 \mathrm{~min}$, respectively). There was no significant gender difference of sleep efficiency $(85.6 \pm 10.5 \%$ versus $86.3 \pm 12.1 \%$, respectively). Mean and minimum oxygen desaturation were similar between genders $(95.6 \pm 1.7 \%$ versus $95.9 \pm 2.0 \%$, $78.7 \pm 14.1 \%$ versus $82.6 \pm 8.8 \%)$.

\section{Discussion}

The male to female ratio in our study was 3.59:1, which was consistent with previous studies ${ }^{4-6}$. According to previous literature, most of the female patients with OSAS were in menopause and older than male patients. Raluca et al pointed out that hormones especially progesterone might protect premenopausal women from developing OSAS and testosterone may be a risk factor of $\mathrm{OSAS}^{10}$.

Our study found that male patients were taller and heavier than female patients. According to the report on Nutrition and Chronic Disease Status of Chinese Residents (2015), the average height for males and females aged over 18 years old were $167.1 \mathrm{~cm}$ and $155.8 \mathrm{~cm}$ respectively, which was similar to our findings. Literature about the gender differences in BMI among OSAS patients were mixed. Most of the studies reported that females had higher BMI than males ${ }^{11,12}$ whereas other studies including our study showed that BMI could not play a role in the gender differences of OSAS patients ${ }^{13}$.

Our study showed that daytime sleepiness and snoring symptoms were similar between male and female patients with OSAS, and males showed more witnessed apneas. Andressa Silva et al. ${ }^{14}$ found that snoring and sleepiness were similarly common in females and males, but females went to see a doctor more often with a chief complaint of insomnia, which may partly explain the phenomenon of lower diagnostic rate of OSAS in females.

Our study showed that female patients had longer duration of SWS. Fewer studies have investigated gender differences in the SWS, and the data are more conflicting. Few studies indicated that there were no gender differences in the amount of SWS ${ }^{15}$, whereas other studies reported that males may have sustained reductions in SWS as compared with females over the lifespan ${ }^{16-18}$. It is well known that AHI is significantly decreased during SWS ${ }^{19}$ and there is an attempt to explain it by higher upper-airway muscle activity and/or lower upper-airway collapsibility during SWS 20,21 .

Our study found that males have more severe OSAS than females, which was consistent with most of the previous studies ${ }^{6,12,22-24}$. The pathophysiologic mechanisms have not been well clarified. Differences in the dynamic properties of the upper airway may play a critical role. Elisa Perger et al. ${ }^{25}$ suggested that upper airways were stiffer in females than in males, so that females were less susceptible to collapse and males had greater pharyngeal 


\begin{tabular}{|c|c|c|c|c|}
\hline Variables & Female & Male & Statistics & $P$ \\
\hline \multicolumn{5}{|c|}{ Demographic and clinical data } \\
\hline Age & $48.4(12.6)$ & $43.4(12.4)$ & $\mathrm{F}=8.360$ & $0.004^{* *}$ \\
\hline ESS scoring & $8.2(5.6)$ & $8.7(5.9)$ & $\mathrm{F}=0.481$ & 0.488 \\
\hline Height $(\mathrm{cm})$ & $157.5(5.0)$ & $169.8(6.0)$ & $\mathrm{F}=228.69$ & $0.000^{* *}$ \\
\hline Weight (kg) & 61.1(9.6) & $74.9(11.5)$ & $F=79.01$ & $0.000^{* *}$ \\
\hline BMI & $24.6(3.7)$ & $25.9(3.5)$ & $F=7.420$ & $0.007^{* *}$ \\
\hline \multicolumn{5}{|l|}{ Blood pressure (mmHg) } \\
\hline SBP before sleep & $119.7(12.9)$ & 125.1(15.5) & $F=6.546$ & $0.011^{* *}$ \\
\hline DBP before sleep & $72.1(9.9)$ & $75.4(11.9)$ & $\mathrm{F}=4.305$ & $0.039^{* *}$ \\
\hline SBP in the next morning & $119.4(13.6)$ & $124.3(16.1)$ & $\mathrm{F}=4.834$ & $0.029^{* *}$ \\
\hline DBP in the next morning & $73.4(9.7)$ & $77.5(11.8)$ & $F=6.189$ & $0.013^{* *}$ \\
\hline \multicolumn{5}{|l|}{ Sleep parameters } \\
\hline \multicolumn{5}{|l|}{ Sleep latency (min) } \\
\hline N1 sleep & $14.1(15.4)$ & $9.4(17.3)$ & $F=3.997$ & $0.046^{* *}$ \\
\hline N2 sleep & $23.9(29.9)$ & $16.7(24.1)$ & $\mathrm{F}=4.202$ & $0.041^{* *}$ \\
\hline N3 sleep & $64.3(76.8)$ & $79.6(92.6)$ & $F=1.525$ & 0.218 \\
\hline REM sleep & $146.8(84.1)$ & 131.5(77.4) & $\mathrm{F}=1.942$ & 0.165 \\
\hline TST (min) & $451.7(69.8)$ & $455.1(68.7)$ & $\mathrm{F}=0.130$ & 0.719 \\
\hline REM (min) & $67.4(30.8)$ & $71.9(28.3)$ & $\mathrm{F}=1.222$ & 0.270 \\
\hline NREM (min) & $384.2(62.3)$ & $397.6(242.1)$ & $F=0.198$ & 0.657 \\
\hline $\mathrm{N} 1+\mathrm{N} 2(\min )$ & $331.5(67.8)$ & $359.8(240.6)$ & $F=0.892$ & 0.346 \\
\hline SWS (min) & $52.7(41.5)$ & $37.8(27.3)$ & $F=12.008$ & $0.001^{* *}$ \\
\hline Sleep efficiency & $85.6(10.5)$ & $86.3(12.1)$ & $\mathrm{F}=0.174$ & 0.677 \\
\hline \multicolumn{5}{|l|}{ Respiratory parameters } \\
\hline Micro-arousals events & $100.1(77.0)$ & $161.2(125.5)$ & 14.157 & $0.000^{* *}$ \\
\hline Arousals events & $17.3(9.0)$ & $18.5(11.6)$ & 0.608 & 0.436 \\
\hline MAI & $15.0(10.4)$ & $24.5(17.0)$ & 18.556 & $0.000^{* *}$ \\
\hline AHI & $24.3(19.4)$ & $33.9(25.5)$ & $\mathrm{F}=7.970$ & $0.005^{* *}$ \\
\hline Mean $\mathrm{SpO}_{2}$ & $95.9(2.0)$ & $95.6(1.7)$ & $\mathrm{F}=0.853$ & 0.356 \\
\hline Lowest $\mathrm{SpO}_{2}$ & $82.6(8.8)$ & $78.7(14.1)$ & $F=4.476$ & $0.035^{* *}$ \\
\hline \multicolumn{5}{|l|}{ Snoring } \\
\hline Frequency & $179.1(188.4)$ & $20.2 .1(191.9)$ & $\mathrm{F}=0.742$ & 0.390 \\
\hline Duration (min) & 70.(77.5) & $67.5(155.5)$ & $\mathrm{F}=0.016$ & 0.900 \\
\hline Percentage (\%) & $15.0(16.4)$ & $12.7(13.9)$ & $F=1.293$ & 0.256 \\
\hline \multicolumn{5}{|l|}{ Obstructive apnea } \\
\hline Frequency & $85.9(17.9)$ & $131.4(186.2)$ & $\mathrm{F}=7.221$ & $0.008^{* *}$ \\
\hline Maximum duration (min) & $30.2(19.2)$ & $41.3(25.4)$ & $\mathrm{F}=10.722$ & $0.001^{* *}$ \\
\hline \multicolumn{5}{|l|}{ Centric apnea } \\
\hline Frequency & $1.5(3.6)$ & $4.1(8.9)$ & $F=5.284$ & $0.022^{* *}$ \\
\hline Maximum duration (min) & $6.2(7.6)$ & $11.5(10.5)$ & $\mathrm{F}=14.508$ & $0.000^{* *}$ \\
\hline \multicolumn{5}{|l|}{ Hypopnea } \\
\hline Frequency & $115.7(78.8)$ & $105.5(74.4)$ & $\mathrm{F}=0.945$ & 0.332 \\
\hline Maximum duration (min) & $45.4(14.1)$ & $47.2(12.2)$ & $\mathrm{F}=1.120$ & 0.290 \\
\hline \multicolumn{5}{|l|}{ Complex sleep apnea } \\
\hline Frequency & $2.7(6.2)$ & $18.2(46.3)$ & $F=7.345$ & $0.007^{* *}$ \\
\hline Maximum duration (min) & 12.1(15.9) & $26.1(23.6)$ & $F=20.353$ & $0.000^{* *}$ \\
\hline Awake time (min) & $54.0(52.4)$ & $55.2(58.5)$ & $\mathrm{F}=0.022$ & 0.882 \\
\hline Supine position (\%) & $63.8(21.3)$ & $52.3(24.2)$ & $\mathrm{F}=12.099$ & $0.001^{* *}$ \\
\hline
\end{tabular}

Table 3. Univariate logistic regression analysis of gender differences of clinical and polysomnographic findings with OSAS. MAI microarousal index, AHI apnea-hypopnea index, SWS slow wave sleep, TST Total sleep time, $S B P$ systolic blood pressure, $D B P$ diastolic blood pressure, ESS Epworth Sleepiness Scale. ${ }^{*} P<0.05$.

collapsibility. In addition, female hormones may increase the upper airway dilator muscles tone, which helped to prevent airway collapse ${ }^{26}$. 


\begin{tabular}{|l|l|l|l|}
\hline Variables & \multicolumn{1}{|l|}{ B } & $\operatorname{Exp}(\mathbf{B})$ & $\boldsymbol{P}$ \\
\hline Height & 0.364 & 1.438 & $0.000^{\star *}$ \\
\hline Weight & 0.093 & 1.098 & $0.005^{\star *}$ \\
\hline SBP in the morning & 0.040 & 1.041 & $0.030^{\star *}$ \\
\hline Duration of SWS & -0.024 & 0.976 & $0.003^{\star *}$ \\
\hline Frequency of micro-arousals & 0.010 & 1.010 & $0.007^{\star *}$ \\
\hline AHI & -0.083 & 0.921 & $0.001^{\star *}$ \\
\hline Frequency of complex sleep apnea & 0.090 & 1.095 & $0.047^{\star *}$ \\
\hline MAI & & & 0.684 \\
\hline Frequency of centric sleep apnea & & & 0.079 \\
\hline Frequency of obstructive apnea & & & 0.853 \\
\hline Maximum duration of complex apnea & & & 0.494 \\
\hline Maximum duration of centric apnea & & & 0.604 \\
\hline Maximum duration of obstructive apnea & & & 0.707 \\
\hline BMI & & & 0.967 \\
\hline Age & & & 0.931 \\
\hline SBP before sleep & & & 0.527 \\
\hline DBP before sleep & & & 0.627 \\
\hline DBP in the morning & & & 0.878 \\
\hline N1 latency & & 0.393 \\
\hline N2 latency & & 0.811 \\
\hline Minimum S $\mathrm{O}_{2}$ & & 0.930 \\
\hline Supine position (\%) & & 0.269 \\
\hline
\end{tabular}

Table 4. Multivariate logistic regression analysis of gender differences of clinical and polysomnographic findings with OSAS. MAI microarousal index, $A H I$ apnea-hypopnea index, SWS slow wave sleep, TST Total sleep time, $S B P$ systolic blood pressure, $D B P$ diastolic blood pressure. ${ }^{* *} P<0.05$.

Our study found that systolic blood pressure in the morning was significantly higher in males than in females. The micro-arousal events were also greater in males. Recently emerging evidence suggests that there is a causal link between OSAS and hypertension, and hypertension represents an independent risk factor of OSAS. In addition, the existence of micro-arousals is enough to cause an hypertension peak which might partly explain the results ${ }^{27}$.

Limitations of the study need to be pointed out. The patients enrolled in the study were from only one sleep disorder center, which might result in potential sampling bias. Larger, multi-center studies are required to explore the impact of gender on OSAS. A better understanding of gender differences of OSAS will be useful in better recognition, intervention and treatment of the syndrome in females.

\section{Methods}

Participants. A total of 303 adult patients with OSAS were referred to the sleep disorder center of department of psychosomatics, Sichuan Academy of Medical Sciences \& Sichuan Provincial People's Hospital from 2017 to 2019. All patients completed physical examination, Epworth Sleepiness Scale (ESS) and PSG.

The study was reviewed and approved by the Ethics Committee of Sichuan Academy of Medical Sciences \& Sichuan Provincial People's Hospital, and conducted in accordance with the Declaration of Helsinki.

Questionnaire. The most important scale for the assessment of daytime sleepiness is ESS published in 1991 by Murray Johns ${ }^{28}$. It consists of a self-administered questionnaire that investigates the extent of daytime sleepiness specifically and in a very simple manner. There are 8 items in ESS and subjects are asked to rate on a 4-point scale (0-3) his/her chances of dozing in each of 8 different situations that are often encountered in daily life. Arbitrarily, a score of $\geqq 12$ has been suggested as being abnormal and an indicator of excessive daytime sleepiness $^{29}$.

PSG data collection. The gold standard diagnostic method for OSAS is a full-night PSG ${ }^{30}$. The frequency of episodes of apnea and/or hypopnea per hour of sleep, also known as AHI, as well as the lowest observed oxyhemoglobin saturation during sleep is used as the main criteria for severity assessment.

All patients had to have a minimum of $8 \mathrm{~h}$ of monitored sleep in the sleep disorder center. They underwent nocturnal PSG monitoring (Philips Alice Version 6, Netherland) using 6 scalp electrodes (C3, C4, F3, F4, O1 and $\mathrm{O} 2$ locations), 2 reference electrodes behind the ears (left [A1] and right [A2] mastoid areas), 3 electromyographic electrodes over the submental muscles, 4 electromyographic electrodes over the leg muscles, 2 electrooculographic electrodes, one ground electrode and nasal flow detector. Pulse oximeter was used to obtain nocturnal oximetry recordings. Electrocardiogram was used to obtain rhythm of the heart. The AHI documented the number of apnea-plus-hypopnea incidents every hour during sleep ${ }^{31}$. 
Statistics. Statistical analyses were performed with SPSS 26.0 for mac. The summary of descriptive statistics was presented as mean (with SD) for continuous variables and as frequencies (with percentages) for categorical variables. ANOVA was used for comparison of quantitative data. Univariate and multivariate logistic regression analyses were conducted to identify gender differences of clinical and polysomnographic findings with OSAS. Statistically significant difference was considered if $P$ value $<00.05^{31}$.

Ethics approval and consent to participate. The research was approved by the Ethics Committee of Sichuan Academy of Medical Sciences \& Sichuan Provincial People's Hospital. Written informed consent was obtained from all the participants.

Consent to publish. Written informed consent was obtained from all participants for the publication of any potentially identifiable images or data included in this article.

\section{Data availability}

The data used and analyzed during the current study are available from the corresponding author on reasonable request.

Received: 18 September 2020; Accepted: 3 March 2021

Published online: 15 March 2021

\section{References}

1. Park, J. G., Ramar, K. \& Olson, E. J. Updates on definition, consequences, and management of obstructive sleep apnea. Mayo Clin. Proc. 86, 549-554; quiz 554-545, doi:https://doi.org/10.4065/mcp.2010.0810 (2011).

2. Fekete, K. et al. Resting energy expenditure in OSAS: the impact of a single CPAP application. Sleep Breath 20, 121-128. https:// doi.org/10.1007/s11325-015-1194-y (2016).

3. Chen, D.-D., Huang, J.-F., Lin, Q.-C., Chen, G.-P. \& Zhao, J.-M. Relationship between serum adiponectin and bone mineral density in male patients with obstructive sleep apnea syndrome. Sleep breath 21(2), 557-564 (2017).

4. Bozkurt, M. K. et al. Gender differences in polysomnographic findings in Turkish patients with obstructive sleep apnea syndrome. Eur. Arch. Otorhinolaryngol. 265, 821-824. https://doi.org/10.1007/s00405-007-0554-z (2008).

5. Senaratna, C. V. et al. Prevalence of obstructive sleep apnea in the general population: a systematic review. Sleep Med. Rev. 34, 70-81. https://doi.org/10.1016/j.smrv.2016.07.002 (2017).

6. Heinzer, R. et al. Prevalence of sleep-disordered breathing in the general population: the HypnoLaus study. Lancet Respir. Med. 3, 310-318. https://doi.org/10.1016/S2213-2600(15)00043-0 (2015).

7. Karaduman, M. et al. Evaluation of obstructive sleep apnea symptoms in pregnant women with chronic disease. J. Matern. Fetal Neonatal Med. 29, 3379-3385. https://doi.org/10.3109/14767058.2015.1127346 (2016).

8. Research, N. C. o. S. D. 2003 National Sleep Disorders Research Plan. Sleep 26(3), 253-257 (2003).

9. Tufik, S., Santos-Silva, R., Taddei, J. A. \& Bittencourt, L. R. Obstructive sleep apnea syndrome in the Sao Paulo Epidemiologic Sleep Study. Sleep Med. 11, 441-446. https://doi.org/10.1016/j.sleep.2009.10.005 (2010).

10. Bercea, R., Bercea, B. \& Mihăescu, T. Association between the serum level of testosterone and other comorbidities in obstructive sleep apnea. Pneumologia 61(2), 98-101 (2012).

11. Topirceanu, A., Udrescu, L., Udrescu, M. \& Mihaicuta, S. Gender phenotyping of patients with obstructive sleep apnea syndrome using a network science approach. J. Clin. Med. 9, 4025. https://doi.org/10.3390/jcm9124025 (2020).

12. Erdemir Işık, M., Gulbay, B., Çiftci, F. \& Acıcan, T. Polysomnographic, demographic and clinic differences between male and female obstructive sleep apnea patients. Tuberk Toraks 68(4), 361-370 (2020).

13. Vagiakis, E. et al. Gender differences on polysomnographic Wndings in Greek subjects with obstructive sleep apnea syndrome. Sleep Med. 7, 424-430 (2006).

14. Silva, A. et al. Gender differences in sleep patterns and sleep complaints of elite athletes. Sleep Sci. 12, 242-248. https://doi. org/10.5935/1984-0063.20190084 (2019).

15. Krishnan, V. \& Collop, N. A. Gender differences in sleep disorders. Curr. Opin. Pulm. Med. 12, 383-389. https://doi.org/10.1097/01. mcp.0000245705.69440.6a (2006).

16. Mokhlesi, B., Pannain, S., Ghods, F. \& Knutson, K. L. Predictors of slow-wave sleep in a clinic-based sample. J. Sleep Res. 21, 170-175. https://doi.org/10.1111/j.1365-2869.2011.00959.x (2012).

17. Yetton, B. D., McDevitt, E. A., Cellini, N., Shelton, C. \& Mednick, S. C. Quantifying sleep architecture dynamics and individual differences using big data and Bayesian networks. PLoS ONE 13, e0194604. https://doi.org/10.1371/journal.pone.0194604 (2018).

18. Luca, G. et al. Age and gender variations of sleep in subjects without sleep disorders. Ann Med 47, 482-491. https://doi. org/10.3109/07853890.2015.1074271 (2015).

19. Koutsourelakis, I., Lamprou, K., Vagiakis, E. \& Zakynthinos, S. Resolution of apnoeas in slow wave sleep. Sleep Breath 20, 819-820. https://doi.org/10.1007/s11325-015-1275-y (2016).

20. McSharry, D. G. et al. A mechanism for upper airway stability during slow wave sleep. Sleep 36, 555-563. https://doi.org/10.5665/ sleep.2544 (2013).

21. Carberry, J. C., Jordan, A. S., White, D. P., Wellman, A. \& Eckert, D. J. Upper airway collapsibility (pcrit) and pharyngeal dilator muscle activity are sleep stage dependent. Sleep 39, 511-521. https://doi.org/10.5665/sleep.5516 (2016).

22. Mieno, Y. et al. Gender differences in the clinical features of sleep apnea syndrome. Intern. Med. 57, 2157-2163. https://doi. org/10.2169/internalmedicine.7570-16 (2018).

23. Saldias Penafiel, F. et al. Gender differences in clinical features and performance of sleep questionnaires in adults with obstructive sleep apnea syndrome. Rev. Med. Chil. 147, 1291-1302. https://doi.org/10.4067/s0034-98872019001001291 (2019).

24. Basoglu, O. K. \& Tasbakan, M. S. Gender differences in clinical and polysomnographic features of obstructive sleep apnea: a clinical study of 2827 patients. Sleep Breath 22, 241-249. https://doi.org/10.1007/s11325-017-1482-9 (2018).

25. Perger, E., Mattaliano, P. \& Lombardi, C. Menopause and sleep apnea. Maturitas 124, 35-38. https://doi.org/10.1016/j.matur itas.2019.02.011 (2019).

26. Asavasupreechar, T., Saito, R., Edwards, D. P., Sasano, H. \& Boonyaratanakornkit, V. Progesterone receptor isoform B expression in pulmonary neuroendocrine cells decreases cell proliferation. J. Steroid Biochem. Mol. Biol. 190, 212-223 (2019).

27. Ciccone, M. M. et al. Is there a correlation between OSAS duration/severity and carotid intima-media thickness?. Respir. Med. 106, 740-746. https://doi.org/10.1016/j.rmed.2011.12.016 (2012).

28. Johns, M. W. A new method for measuring daytime sleepiness: the Epworth sleepiness scale. Sleep 14, 540-545. https://doi. org/10.1093/sleep/14.6.540 (1991). 
29. Dauvilliers, Y. et al. Long-term use of pitolisant to treat patients with narcolepsy: Harmony III Study. Sleep 42(11), zsz74 (2019). 30. Hug, M. et al. Screening for obstructive sleep apnea among hospital outpatients. PLoS ONE 13, e0198315 (2018).

31. Zhou, X. et al. Risk factors associated with the severity of obstructive sleep apnea syndrome among adults. Sci. Rep. 10, 13508. https://doi.org/10.1038/s41598-020-70286-6 (2020).

\section{Acknowledgements}

The study was financially supported by the projects (grant number: 2016LY12) from Sichuan Academy of Medical Sciences \& Sichuan Provincial People's Hospital. We would like to thank Dr Fang Luo, Dr Xi Yu and Dr Yan Jiang for their help in collecting the data. We would like to thank Dr Zhe Li for her advice in improving the quality of the manuscript.

\section{Author contributions}

All authors contributed to the study conception and design. Material preparation, data collection and analysis were performed by Q.L., S.P.L. and Z.Y.P. and F. L. The first draft of the manuscript was written by X.Z., B.Z. and Z.L provided valuable advice. All authors commented on previous versions of the manuscript. All authors read and approved the final manuscript.

\section{Competing interests}

The authors declare no competing interests.

\section{Additional information}

Correspondence and requests for materials should be addressed to X.Z.

Reprints and permissions information is available at www.nature.com/reprints.

Publisher's note Springer Nature remains neutral with regard to jurisdictional claims in published maps and institutional affiliations.

(c) (i) Open Access This article is licensed under a Creative Commons Attribution 4.0 International License, which permits use, sharing, adaptation, distribution and reproduction in any medium or format, as long as you give appropriate credit to the original author(s) and the source, provide a link to the Creative Commons licence, and indicate if changes were made. The images or other third party material in this article are included in the article's Creative Commons licence, unless indicated otherwise in a credit line to the material. If material is not included in the article's Creative Commons licence and your intended use is not permitted by statutory regulation or exceeds the permitted use, you will need to obtain permission directly from the copyright holder. To view a copy of this licence, visit http://creativecommons.org/licenses/by/4.0/.

(C) The Author(s) 2021 